\title{
Um mundo para descobrir *
}

Onde conduz o diálogo que, graças à ciência, o homem mantém com a natureza? Há ainda pouco tempo havia quem acreditasse que este diálogo tinha decifrado o enigma da existência. Num texto bem conhecido, Lévy-Bruhl exprime-se com uma segurança tranquila: "O nosso sentimento permanente de segurança intelectual está tão bem alicerçado que não vemos como ele poderia ser abalado; porque, mesmo supondo a descoberta súbita de um fenómeno misterioso do qual desconhecêssemos completamente as causas, nós não deixariamos de estar convencidos de que a nossa ignorância apenas seria provisória, de que as causas existiriam e que seriam descobertas mais cedo ou mais tarde. Podemos assim dizer que a natureza em que vivemos é intelectualizada a priori. Ela é ordem e razão, tal como o é o espírito que sobre ela reflecte e que nela se movimenta. A nossa actividade quotidiana implica, até nos seus pormenores mais insignificantes, uma confiança tranquila e perfeita na universalidade das leis naturais". (')

Actualmente estas afirmações parecem-nos estranhas. Como é possível que a nossa visão do mundo tenha sido tão profundamente alterada em apenas alguns decénios? É no entanto um facto que tal aconteceu. Tanto no domínio das ciências, como no domínio artístico ou social, o nosso tempo conheceu transformações sem paralelo. $\mathrm{O}$ século $\mathrm{XX}$ iniciou-se com duas revoluções decisivas no pensamento científico: a relatividade e a mecânica quântica.

$\mathrm{Na}$ perspectiva dos primeiros anos deste século, foi o trabalho de Einstein sobre a relatividade em 1905 que primeiro abalou todas as certezas até então adquiridas, e que mostrou que a ciência abre o caminho que conduz à descoberta das estruturas ocultas do universo físico. Nas suas notas autobiográficas, Einstein escreveu que o deslumbramento é um elemento essencial da criatividade científica. Creio que isso é verdade para todos nós: o trabalho de Einstein revelou-nos um mundo desconhecido e fez-nos compreender que estávamos no início de uma nova era, com tudo o que isso comporta de esperança, mas também de risco de saídas em falso.

Hoje em dia, quase oitenta anos depois do trabalho de Einstein, falamos de duas outras revoluções que transformam o destino da humanidade: a revolução biológica e a revolução informática.

Penso que todas estas mutações correspondem a uma alteração fundamental do diálogo entre o homem e a natureza. Há já muito tempo que sabiamos vivermos num mundo pluralista, que contém componentes deterministas e reversíveis, mas também componentes aleatórias e irreversíveis. Podemos identificar fenómenos deterministas como o movimento do pêndulo ou o movimento da Lua em torno da Terra; sabemos que no caso do pêndulo ideal, sem atrito, o movimento é reversível. Neste caso, como em todas as situações reversíveis, futuro e passado desempenham o mesmo papel: prever o movimento futuro do pêndulo ou descrever o movimento passado reduzem-se ao mesmo problema matemático. Mas, por outro lado, existem também processos irreversíveis como a difusão de dois líquidos ou as reacções químicas nos quais, pelo contrário, o sentido do tempo desempenha um papel essencial. Se partirmos, no momento presente, de uma distribuição não uniforme da temperatura, esta distribuição tornar-se-á uniforme no futuro. Ninguém ainda observou um sistema no qual a aproximação ao equilibrio se realizasse no sentido do nosso passado. Temos assim de admitir que existem fenómenos aleatórios se não quisermos ser confrontados com a objecção segundo a qual o desenvolvimento de todas as espécies vivas estaria programado desde o Big-Bang.

$\mathrm{O}$ que se alterou desde o início deste século, foi a nossa apreciação àcerca da importância relativa destas quatro categorias. Os físicos eram então unânimes em considerar que as leis fundamentais do Universo eram deterministas e reversíveis. Os processos que saíam deste quadro surgiam como anomalias, devidas a uma aparente complexidade, ela mesma resultante da nossa ignorância ou da nossa falta de controle sobre as variáveis.

Ora, neste fim de século, somos cada vez mais numerosos os que pensamos que as leis fundamentais são irreversíveis e aleatórias, ao passo que as leis reversíveis e deterministas, de que não contestamos a existência, apenas se aplicam a situações limite: processos "exemplares", no sentido em que o são as histórias que contamos às crianças antes de as confrontarmos com problemas mais concretos. As grandes mutaçðes que assinalei surgem como momentos deste movimento histórico das ciências no sentido do irreversível e do imprevisível.

É o que mostram os acontecimentos que se sucederam às revoluções instauradas pela relatividade e pela mecânica quântica. Uma e outra pretendiam introduzir na mecânica clássica as correcções tornadas necessárias uma vez reconhecido o papel de constantes

\footnotetext{
* Publicado com a autorização do autor. Traduzido de Nouvelles de la Science et des Technologies, vol. 2 (Março de 1984), por Vitor D. Teodoro.

a Prémio Nobel (1977); Université Libre de Bruxelles (Service de Chimie-Physique II) e University of Texas at Austin (Center of Statistical Mechanics and Thermodynamics).
} 
universais como c (velocidade da luz no vazio) e h (constante de Planck). Nesta primeira etapa, quer a revolução relativística quer a revolução quântica, conservaram o espírito da mecânica clássica, mas vemos hoje em dia que bem cedo alteraram o seu rumo de modo inesperado. A mecânica quântica trata actualmente, na sua parte mais significativa, da instabilidade das particulas elementares. Sabemos hoje que existe uma verdadeira "quimica" destas partículas elementares, o que está em contradição flagrante com a ideia de que partiram as teorias atómicas: a saber, de dar um suporte estável e permanente ao mundo em constante mutação.

A evolução da relatividade foi inesperada: começou com o estatuto de uma geometria intemporal, para se tornar em seguida instrumento teórico privilegiado para estudar a história térmica do Universo, principalmente nas suas primeiras fases.

Isto corresponde a uma alteração fundamental. Porque, para além dos problemas cientificos ou tecnológicos que implica, ela induz uma modificação da nossa relação com o mundo: não apenas da relação homem-natureza, mas também, como discutirei adiante, da relação homem-homem.

Não há dúvida de que a nossa experiência interior foi sempre marcada pela dimensão aleatória e imprevisível. Não existiria literatura se não existisse a ansiedade ligada à escolha e à irreversibilidade que se atribui ao destino - ou então tratar-se-ia de uma literatura inconcebível para nós, amputada das dimensð̃es do dramático e do trágico. Também só podemos conceber a música associada às noções do imprevisível e do irreversivel.

Pelo contrário, os modelos do mundo nos quais estruturámos a nossa experiência do meio exterior assentavam no determinismo e na reversibilidade. $\mathrm{O}$ facto de a história recente das ciências conduzir à superação deste dualismo é para mim um acontecimento importante na história das ideias, ao mesmo tempo que constitui a garantia de uma cultura menos conflituosa do que foi a cultura ocidental no decurso dos séculos que se seguiram ao triunfo da física newtoniana. Desenvolvi este tema mais detalhadamente no livro "A nova aliança". (2)

É importante notar que a Química e a Física macroscópicas também contribuiram intensamente para este movimento, como adiante se referirá.

É neste quadro conceptual renovado que as revoluções das ciências da vida e da informação encontraram o seu significado pleno. Quando do último Congresso Solvay de Química, os participantes interrogaram-se qual seria a diferença entre a Química Orgânica e a Bioquímica. As substâncias da Química Orgânica são substâncias que nós sintetizamos e que não foram submetidas.a uma evolução pausada por fases de auto-organização como aquela que originou as moléculas biológicas.

Talvez a diferença mais profunda consista em que as moléculas estudadas pela bioquímica devam ser tratadas como objectos históricos, como moléculas que o tempo esculpiu.

Ora, como mostra o texto de Grégoire Nicolis que se publica a seguir, nós começamos a conhecer os mecanismos graças aos quais o tempo se inscreve na matéria. Estamos longe de poder descrever a biogénese; mas podemos desde já mostrar que as raízes do tempo mergulham bem mais profundamente na matéria do que se pensava até há pouco.

Admiramos todos os notáveis progressos da biolo- gia molecular. Mas só teremos uma visão satisfatória do mundo que nos rodeia quando pudermos descrever mais satisfatoriamente os mecanismos que orientam a evolução das moléculas simples para as biomoléculas fundamentais.

A situação é, em certa medida, semelhante no que respeita às ciências da informação. Assim, o conceito de informação deve ser estudado em função dos seus pressupostos, a saber, a existência de um texto e de um leitor. Também neste caso podemos começar a descortinar situações físico-químicas nas quais vemos aparecer estes dois elementos; estamos ainda longe de uma "teoria da inteligência artificial".

Em todos os níveis da investigação contemporânea, desde a Física às Ciências Sociais, passando pelas Ciências Químicas e Biológicas, se coloca a partir de agora o problema da auto-organização, baseada na dialéctica ordem-desordem.

Estou completamente de acordo com as ideias que J. Starobinski desenvolveu num texto recente: $\left({ }^{3}\right)$

"Não existe actualmente nenhum domínio - ciências físicas, ciências humanas, criação artística, instituiçōes jurídicas, vida económica, debates políticos - em que os problemas não nos pareçam apelar para as noções contrastantes de ordem e de desordem, ou para aquelas, mais subtis mas não menos antinómicas, de equilíbrio e de desiquilibrio. Tudo leva a crer que estas noções nos são indispensáveis para interpretar o conjunto de realidades que se nos oferecem em nós e em torno de nós. São meios de compreensão, ferramentas conceptuais às quais recorremos preferencialmente, mesmo que muitas vezes nos pareçam dever ser matizadas, modificadas, ajustadas a novas situações e a dados inéditos. Estamos sem dúvida a caminho de nos afastarmos do estruturalismo: não podemos no entanto deixar de lhe reconhecer o mérito de ter ousado defender uma leitura dos fenómenos culturais de acordo com um imperativo de ordem coerente."

Já foquei o problema da passagem do determinista e do reversível ao aleatório e ao irreversível.

Diversas correntes de pensamento, várias áreas de experimentação, contribuem para esta alteração de concepções. A mecânica quântica e a cosmologia relativista são disso dois exemplos; mas é actualmente numa escala mais próxima da realidade quotidiana, aquela em que trabalham a Química e a Física macroscópicas das "baixas energias", que a mudança de concepções foi mais particularmente notória. $\left({ }^{4}\right)$

Citemos dois exemplos que desafiaram a imaginação da comunidade científica: as células de Bénard e o relógio quiímico de Belousov-Zhabotinski.

${ }^{(2)}$ I. Prigogine e I. Stengers. La nouvelle alliance. Paris, Gallimard, 1979 (a ser publicado brevemente em Portugal pela D. Quixote); uma exposição mais completa pode ser encontrada em Physique, Temps et Devenir. Paris, Masson, 1982.

$\left({ }^{3}\right)$ Jean Starobinski. Ordre et Désordre, comunicação apresentada nos XXIX Encontros Internacionais de Genebra (19-24 de Setembro de 1983).

(4) Uma apresentação geral desta perspectiva pode encontrar-se em: G. Nicolis e I. Prigogine, Self-Organization in Non-equilibrium Systems: from Dissipative Structures to Order through Fluctuations, John Wiley, New York (1977). 
No primeiro exemplo, uma camada horizontal de líquido é submetida a um fluxo de calor a partir da sua face inferior. Para além de um determinado valor crítico do gradiente vertical de temperatura, é possível observar correntes que se manifestam sob a forma de células de convecção de secção hexagonal. Assim, com o afastamento ao equilíbrio que aumenta com a diferença de temperatura entre as placas, o sistema pode auto-estruturar-se. A energia já não é apenas dissipada no caos térmico das moléculas, mas distribui-se, pelo menos em parte, no seu movimento coordenado. O fluxo de energia, e o estado de não-equilíbrio que dele resulta, conduzem a uma estruturação espontânea do sistema.

O relógio químico constitui um fenómeno muito mais espectacular. Consideremos um sistema cujo estado nós controlamos através da admissão e eliminação de componentes. Suponhamos que dois dos componentes são respectivamente formados por moléculas vermelhas e azuis. Deveriamos observar uma mistura bastante homogénea de vermelho e azul com uma eventual predominância local de vermelho ou azul devido às flutuações. Na realidade o que se observa em determinadas condições é que todo o sistema se torna vermelho, depois azul, e depois novamente vermelho: é isto um relógio químico.

Este comportamento macroscópico resulta de correlações de longo alcance entre moléculas, que resultam das condiçōes de não-equilíbrio a que o sistema está submetido, e que permitem o estabelecimento de um ritmo coerente numa escala da ordem do centimetro e do segundo, escalas essas inacessíveis nas condições de equilibrio.

As situaçōes em que os constrangimentos de não-equilibrio conduzem a fenómenos de organização conduzem geralmente a estados múltiplos. A ocorrência do estado observado é um problema probabilistico. A passagem de uma estrutura a outra produz-se de um modo repentino na vizinhança de um ponto de bifurcação. É uma situação análoga à dos fenómenos descontínuos que toda a gente conhece como as mudanças de fase do tipo liquefacção ou solidificação.

Os conceitos de bifurcação e de afastamento do equilibrio penetram actualmente num grande número de domínios do conhecimento. Estes conceitos permitem-nos encarar problemas essenciais perante os quais a ciência clássica estava bloqueada. Vivemos de facto num universo curioso: de um certo ponto de vista ele parece flutuante, turbulento; de um outro ponto de vista parece tratar-se de um universo que terá seleccionado, uma vez por todas, uma via entre várias possíveis.

Um exemplo particularmente notável é-nos dado pelo estudo dos sistemas climáticos. Ao longo da história da Terra, e em particular depois do fim do terciário, o clima sofreu variações profundas e aleatórias que não podem ser explicadas apenas pelas variações do fluxo de energia solar recebido no topo da atmosfera terrestre. As trocas internas ao sistema terrestre implicam uma dinâmica complexa: este sistema pode conter uma multiplicidade de estados de regime estáveis, repartidos por diversas escalas de tempo e entre os quais existem possibilidades de transição. As flutuações internas e externas, associadas à dinâmica interna deste sistema, enriquecem a sua evolução na medida em que Ihe permitem explorar e escolher esses estados. Uma análise qualitativa simples da dinâmica climática evidenciou um fenómeno extremamente surpreendente: variaçðes insignificantes (da ordem de $0,1 \%$ ) do fluxo de energia solar podem ser amplificadas levando o clima a oscilar de uma solução estável para outra. $\left(^{5}\right)$

O que é ainda mais curioso é que os dados sugerem que esta modificação se pode realizar em escalas de tempo curtas.

Estamos pois perante um universo instável, turbulento ao passo que o senso comum sugeriria pelo contrário uma situação que, uma vez estabelecida, apenas evoluiria em escalas de tempo enormes, correspondentes à evolução do Sol.

Mas conhecemos também a situação inversa. Pensemos a título de exemplo na distribuição das partículas e das anti-partículas.

As equaç̃̃es da mecânica quântica são simétricas em partículas e anti-partículas; seria pois de esperar um universo altamente flutuante no que diz respeito à composição em partículas e em anti-partículas. A Química fala-nos também de moléculas simétricas uma das outras, em que as versões "esquerda" e "direita" apresentam poucas propriedades diferentes de um ponto de vista físico-químico. Ora estas moléculas foram objecto de uma selecção muito estável na matéria viva; Pasteur ficou surpreendido com o facto de a matéria viva apresentar compostos de uma pureza quiral perfeita em vez de apresentar uma mistura racémica das duas versð̌es.

Tal como no problema das partículas e das anti-partículas, é a ausência de flutuações que é neste caso surpreendente. Perante a amplitude do fenómeno parece insuficiente invocar como explicação um acontecimento único. O não-equilibrio não conduz apenas a correlações de longo alcance; ele induz também uma forte sensibilidade aos pequenos efeitos. Nas células de Bénard vimos como um sistema hidrodinâmico se torna sensivel ao campo gravítico. Do mesmo modo, o ritmo de certos relógios químicos pode variar em função de pequenas alteraçðes da energia luminosa.

Tudo leva a crer que estes fenómenos de sensibilidade de não-equilíbrio desempenharam, nos fenómenos vivos, um papel fundamental. ( $\left.{ }^{6}\right) \mathrm{O}$ ser vivo não vive apenas de Química; ele incorpora em si resultados construídos em função do campo gravítico, dos campos electromagnéticos, dos diversos ritmos temporais, etc.

Trabalhos recentes falam de mecanismos capazes de seleccionar preferencialmente as versões direita e esquerda de uma molécula, capazes de ser sensiveis a uma diferença da ordem de $10^{-15} \mathrm{kT}$ na energia de activação.

Esta particularidade foi recentemente evidenciada no estudo de modelos numéricos; se fôr confirmada, ela poderá encontrar aplicaçōes em diversos domínios das ciências dos seres vivos e da informação.

Os desenvolvimentos que tenho vindo a evocar conduzem sistematicamente a novos pontos de vista. Um aspecto interessante é o da resposta imunitária do organismo ao cancro. É evidente que um aspecto fundamental deste problema é o da deterioração genética que conduz à formação de moléculas cancerosas. Mas existe um segundo problema: qual será a resposta imu-

${ }^{5}$ ) G. Nicolis, "Aspects of Climatic Transition. Response to a Periodic Forcing”, Tellus 34, 1-9 (1982).

(6) D. Kondepudi, G. W. Nelson, "Chiral Symmetry Breaking in Nonequilibrium Chemical Systems: Time Scales for Chiral Selections, Phys. Rev. Lett., a publicar. 
nitária do organismo? O estudo da dinâmica imunitária mostra a possibilidade de existência de estados múltiplos, possibilidade esta que assume aqui um significado particularmente importante: o organismo pode desenvolver diferentes estados radicalmente distintos: micro-cancros, que podem permanecer inofensivos, ou macro-cancros virulentos.

O problema do cancro não se coloca pois apenas em termos moleculares. Implica outras perspectivas de que só hoje começamos a ter consciência.

\section{$* * *$}

A situação em que se encontra actualmente a ciência resulta em última análise da herança do século XIX. Sabemos que este século foi o da evolução: de Hegel a Darwin e Marx, numerosos discursos procuram reconstruir o percurso das figuras do Espírito, a génese das espécies vivas ou a história das formações sociais. Este florescimento acentuaria de facto o fosso existente entre as ciências naturais e humanas por um lado, e as ciências físicas por outro, sendo estas últimas as herdeiras da grande tradição newtoniana, estranha a qualquer ideia de história. O tempo-ilusão era ainda um tema caro a Einstein que situava os fundamentos da ciência na perspectiva da Eternidade. Não é fácil reconciliar estas duas perspectivas. O problema que nós herdámos do século XIX pode formular-se da seguinte maneira: existirá um paradigma evolutivo comum simultaneamente aplicável aos fenómenos relativamente simples que observamos em física e em química e aos fenómenos complexos que constituem a regra no domínio dos seres vivos e do social? Encontramos mais uma vez o par ordem/desordem evidenciado por Starobinski. Poderemos nós reconhecer mérito aos fenómenos nos quais a ordem se transforma em desordem, como pretendia Boltzmann, e àqueles em que a desordem se transforma em ordem, como parece indicar a evolução das espécies? Por outras palavras, será possivel construir um paradigma único, que englobe simultaneamente a morte e o nascimento das estruturas?

Podemos actualmente começar a dar uma resposta afirmativa a esta interrogação. Resta saber até onde se poderá fazer esta unificação: a teoria do não-equilíbrio está ainda em plena evolução e nesta fase é legitimo ter grandes esperanças. Mas é necessário dizer também que esta questão ultrapassa o contexto interno das ciências e defronta-se com o problema do destino do homem: estará a história enraizada no real? Reconhecemos aqui a interrogação filosófica de Orwell no seu romance 1984 .

Se é ao poder da sociedade que compete reescrever o passado, o tempo não passa de uma ilusão - o que coincide curiosamente com uma tese de Einstein - e a história que os homens procuram escrever e reescrever reduz-se a uma série de flutuações desprovidas de significado. Lembramo-nos do Motto de um controlo total sobre a história, cujas implicaçōes foram desenvolvidas no ano de 1984: «Who controls the past controls the future: who controls the present controls the past"y.

$\mathrm{O}$ pesadelo do tempo roubado ao homem dissipa-se actualmente. O tempo não é uma ilusão como pensava Einstein. $\left({ }^{7}\right)$ Ele está bem enraizado na natureza. Não é a história que é «anti-natural»: muito pelo contrário é a paragem da história que só poderia ser imposta pela força. Mas este ponto de vista sobre o papel fundamental da irreversibilidade coloca novas questões.
Aqui está sem dúvida alguma um problema particularmente difícil que nos coloca à primeira vista perante um paradoxo: as leis fundamentais da física clássica, como as leis de Newton e as da relatividade geral, parecem reversíveis. E no entanto a irreversibilidade é, como acabámos de ver, uma propriedade fundamental. Não podemos abordar aqui este problema pois isso exigiria desenvolvimentos demasiado longos. Digamos resumidamente que ele nos convida a formular um novo conceito de tempo: já não um parâmetro externo destinado a medir deslocamentos, mas uma variável interna, dependente de transformações qualitativas dos sistemas. Este tempo, que exprime a existência de um universo evolutivo, já não tem nada a ver com o tempo newtoniano no qual a história é reduzida a uma simples tautologia.

A partir de agora a ciência é mais complexa, menos abstractamente transparente nas suas linguagens e nos seus ideais. Simultaneamente ela torna-se mais sensível a domínios que ela considerava estarem para além das suas fronteiras. A relação do homem com a natureza fica assim alterada nas suas modalidades mais elementares: com efeito, só nesta perspectiva que incorpora o instável e o irreversível é que a aprendizagem e o acto de medida do físico assumem o seu pleno significado. Que significado teria um acto de medida num mundo em que o amanhã estivesse determinado a partir de hoje? Nestas condições a aprendizagem reduzir-se-ia à leitura de um texto já escrito. Muito mais apaixonante é a aventura científica actual em que, nos dominios mais essenciais, os resultados da experiência não podem ser deduzidos de uma teoria determinista e em que a experiência constitui uma escolha entre diferentes possibilidades.

E até nas relações entre o homem e o homem se encontrarão mais cedo ou mais tarde os efeitos desta renovação das formas do saber. A ética não será mais o resultado de uma escolha puramente "decisionista", destinada a instaurar uma ruptura no seio de um mundo surdo aos nossos valores, de acordo com a fórmula de algumas filosofias pós-kantianas brilhantemente sintetizadas por Monod no seu ensaio $O$ Acaso e a Necessidade. O tempo já não é esse parâmetro inerte que tanto registaria o percurso dos sistemas reversíveis como as tensōes do dever ser humano. Sabemos hoje, e retomando as palavras de Valéry, $\left(^{8}\right)$ que a duração é "construção, reconstrução". Cabe a todos trabalhar nela.

(7) 1. Prigogine, «Between Time and eternity: Nehru and Einsteins, Jawaharlal Nehru Lecture, 1983.

(8) Permito-me remeter para um pequeno estudo "L'actualité de la conception du Temps chez Valérym,, apresentado num colóquio realizado em Montpellier em 1982 organizado por Judith Robinson-

- Valéry, e cujas actas foram publicadas posteriormente na colectânea Fonctions de l'Esprit, Hermann, Paris, 1983. 